\title{
DESIGN DE SERVIÇOS E A QUALIDADE DO PROJETO DE AMBIENTES CORPORATIVOS
}

VISBOP

UBERLANDIA 2019

\author{
BRITTES, Gicele Aparecida da Silva
}

Universidade Federal de Juiz de Fora, e-mail: gicelebrittes77@gmail.com

UNANUE, Mariane Garcia

Universidade Federal de Juiz de Fora, e-mail: mariane.unanue@ufjf.edu.br

BRAIDA, Frederico

Universidade Federal de Juiz de Fora/Universidade Tecnológica Federal do Paraná, e-mail: frederico.braida@ufjf.edu.br

\begin{abstract}
RESUMO
Este artigo é resultado de uma pesquisa de mestrado em desenvolvimento junto ao Programa de Pós-graduação em Ambiente Construído da Universidade Federal de Juiz de Fora. Seu conteúdo aborda como o design de serviços vem sendo trabalhado no âmbito do ambiente construído. Para tanto, o objetivo geral do estudo é evidenciar as contribuições do design de serviços para o projeto de espaços corporativos. A hipótese com a qual se trabalha é que o design de serviços pode ser utilizado como uma estratégia projetual de espaços terciários, superando as metodologias tradicionais na busca pela qualidade do projeto. Para atingir 0 objetivo proposto, utiliza-se como parte do processo metodológico uma pesquisa do tipo qualitativa na qual a revisão sistemática de literatura - RSL - é o meio pelo qual os dados foram obtidos. Os resultados indicam que a utilização das ferramentas e técnicas do design de serviços no espaço corporativo de serviços pode contribuir para a qualidade e gestão do ambiente construído.
\end{abstract}

Palavras-chave: Design de serviços, Espaço Corporativo, Ambiente Construído, Qualidade do Projeto.

\begin{abstract}
This article is the result of a master's degree research on the Program in Built Environment of the Federal University of Juiz de Fora. Therefore, the overall objective of the study is to highlight the contributions of service design to the design of corporate spaces. The hypothesis is that service design can be used by corporate spaces as a project strategy of tertiary spaces that allows overcoming traditional methodologies in the quest for project quality. To reach the proposed objective, a qualitative research is used as part of the methodological process in which the systematic review of the literature - SRL - is the means by which the data were obtained. The results indicate that the use of the tools and techniques of service design in the corporate service space can contribute to the quality and management of the built environment.
\end{abstract}

Keywords: Service Design, Corporate Space, Build Environment, Project Quality.

\section{INTRODUÇÃO}

Para Mozota (2003), a cada dia a gestão do design e sua utilização dentro das empresas vêm se tornando parte das ações estratégicas. Contudo, o valor do design nos processos de inovação sempre esteve vinculado à inovação por meio do produto, uma visão que contraria essa lógica (HINNIG, R.; FIALHO, F. A. P., 2009).

BRITTES, G. A. S.; UNANUE, M. G.; BRAIDA, F. Design de serviços e a qualidade do projeto de ambientes corporativos. In: SIMPÓSIO BRASILEIRO DE QUALIDADE DO PROJETO NO AMBIENTE CONSTRUÍDO, 6., 2019, Uberlândia. Anais... Uberlândia: PPGAU/FAUeD/UFU, 2019. p. 295-305. DOI https://doi.org/10.14393/sbqp19029. 
Introduzido pela primeira vez na Alemanha, na década de 1990, através dos estudos de Michael Erlhoff, o design de serviços pode ser entendido como um novo recurso que conecta métodos e ferramentas de áreas distintas do conhecimento (STICKDORN; SCHNEIDER, 2014). Ele representa uma possibilidade para que as organizações projetem serviços cada vez mais próximos das necessidades e desejos dos usuários.

Projetar serviços que ao mesmo tempo satisfaçam as necessidades dos usuários e signifiquem um custo menor para as empresas é um dos objetivos que as organizações contemporâneas podem atingir ao utilizarem os princípios e ferramentas do design de serviços. Para Moritz (2005), o alcance dessa meta é possível porque ele é capaz de projetar serviços que beneficiem tanto as organizações quanto as pessoas que necessitam utilizar este $s$ serviços.

Diante desse cenário, este artigo traz a seguinte questão: Como o design de serviços pode contribuir para o projeto e gestão de espaços corporativos? Acredita-se que o design de serviços possa romper com as metodologias tradicionais e melhorar a qualidade dos projetos, visando à valorização da experiência dos usuários e à inovação no ambiente construído.

Tendo em vista as possibilidades de utilização do design de serviços para o projeto e gestão holísticos do ambiente construído, este artigo tem por objetivo pontuar algumas contribuições do design de serviços para a qualidade do projeto, como especial ênfase em projetos de espaços corporativos.

\section{O DESIGN DE SERVIÇOS}

O design de serviços ajuda a criar novos serviços e a melhorar aqueles já existentes, de maneira a fazê-los mais úteis, utilizáveis e desejáveis para os consumidores e eficientes e eficazes para as empresas (MORITZ, 2005).

Embora os estudos no campo da inovação já sejam bastante promissores, acredita-se que, tendo em vista o novo perfil dos consumidores, torna-se fundamental associar a esta perspectiva as expertises do design. Segundo a Industrial Designers Society for América - IDSA (2012), o design é a atividade profissional que cria e desenvolve conceitos e especificações capazes de otimizar desde as funções até o valor e a aparência de produtos e sistemas de maneira satisfatória tanto para usuários quanto fabricantes. Para Fassi; Galluzzo; Marlow (2018), o design é o campo exploratório onde se juntam as transformações e manipulações de um dado espaço.

Com uma sociedade cada vez mais baseada na experiência, do que propriamente na produção e consumo, um serviço bem projetado pode deixar as pessoas felizes, seguras e, de certa maneira, criar vínculos duradouros entre o usuário e o provedor dos serviços (PINHEIRO, 2015). Para Pinheiro (2015), os serviços são jornadas que resultam da junção entre comportamento do usuário e processo.

A partir do exposto, é possível entender a relação intrínseca entre provedores dos serviços e usuários, pois sua performance está ligada a todos os pontos de contato, isto é, serviços dependem de todas as pessoas envolvidas; talvez por isso os melhores serviços sejam aqueles fáceis de aprender e dominar. 
De acordo com Solomon (2016 apud UNANUE, 2013), a decisão entre o que deve ou não ter nossa atenção é baseada exclusivamente nas visões de mundo, concepções, desejos e experiências. Para Pine e Gilmore (1998), a experiência é sempre individual e, mesmo considerando a existência de diferenciação entre serviços e experiências, tal como serviço e produto, ela será sempre única na mente do consumidor. Como vantagem dessa abordagem, está o surgimento da possibilidade de adição de valor na diferenciação de serviços, pois a experiência em serviços está relacionada a um tipo de resultado econômico não articulado (PINE; GILMORE, 1998).

Essas experiências revelam a necessidade de fazer o espaço corporativo cada vez mais coerente com as necessidades e desejos de seus diferentes stakeholders.

Experiências, como bens e serviços, precisam atender a uma necessidade do cliente, elas precisam funcionar; e elas têm que ser fornecidas. Assim como os bens e serviços resultam de um processo interativo de pesquisa, design e desenvolvimento, as experiências derivam de um processo interativo de exploração, criação de scripts e preparação - capacidades que os comerciantes de experiências aspirantes precisam dominar (PINE; GILMORE, 1998, p. 102, tradução nossa).

Neste sentido, identificar o tipo de sensação ou emoção que se quer produzir nos funcionários é fundamental para estimular a criatividade e todas as condições para melhorar a qualidade e as interações entre consumidores e empresas.

Para Stickdorn e Schneider (2014), o design thinking de serviços é composto por cinco princípios básicos:

(1) A centralidade no usuário: preconiza que todos os serviços sejam pautados pelo olhar do cliente;

(2) Cocriativo: pressupõe que todos os stakeholders devem estar incluídos no processo;

(3) Sequencial: compreende os serviços como parte de uma sequência de ações inter-relacionadas;

(4) Evidente: pressupõe que, embora intangíveis, os serviços sejam visualizados como artefatos físicos;

(5) Holístico: atribui uma visão geral ao ambiente de um serviço.

Para Stickdorn e Schneider (2014), mesmo não havendo linearidade nos processos de design, a aplicação de algumas ferramentas possibilitam articular uma estrutura interativa. $\bigcirc$ quadro a seguir reúne estas ferramentas e suas respectivas atribuições.

Quadro 1 - Ferramentas do design de serviços

\begin{tabular}{|c|c|}
\hline $\begin{array}{c}\text { Ferramentas e } \\
\text { processos }\end{array}$ & \multicolumn{1}{c|}{ Descrição } \\
\hline Blue print & $\begin{array}{c}\text { É um quadro utilizado para mapear uma solução ou informação e } \\
\text { possibilita a previsibilidade e o sucesso de projetos, vinculando } \\
\text { melhores práticas e metodologias utilizáveis assim como artefatos } \\
\text { técnicos e de negócios. Indicado para projetos de integração de }\end{array}$ \\
\hline
\end{tabular}




\begin{tabular}{|c|c|}
\hline & $\begin{array}{l}\text { projetos de informações onde as equipes podem definir, } \\
\text { documentar e gerenciar fluxos de informação. }\end{array}$ \\
\hline Diagrama de causas & $\begin{array}{c}\text { A partir de três círculos circunscritos coloca-se no círculo central as } \\
\text { causas diretas de um problema, no intermediário, coloca-se as } \\
\text { causas indiretas, e no círculo externo, coloca-se os fatores que } \\
\text { contribuem para o surgimento do problema. Indicado para } \\
\text { desenvolver processos de coautoria na resolução de futuros } \\
\text { problemas. }\end{array}$ \\
\hline Mapa conceitual & $\begin{array}{l}\text { Instrumento de representação gráfica que cria conexões entre } \\
\text { ideias e conceitos demonstrando um conhecimento ou uma } \\
\text { estratégia cognitiva. Pode ser utilizado por uma ou várias pessoas. }\end{array}$ \\
\hline Cartões de insights & $\begin{array}{l}\text { Reflexões baseadas em dados reais (pesquisa), traduzidas para } \\
\text { cartões que facilitam manuseio. }\end{array}$ \\
\hline Mapa de empatia & $\begin{array}{c}\text { Instrumento de síntese de informações numa visualização do que } \\
\text { ele diz e sente. Melhora a organização de dados possibilitando a } \\
\text { compreensão de situações de contexto, comportamentos, } \\
\text { preocupações e desejos dos usuários. }\end{array}$ \\
\hline $\begin{array}{l}\text { Workshop de } \\
\text { cocriação }\end{array}$ & $\begin{array}{l}\text { Encontro organizado em forma de atividades em grupo visando } \\
\text { estimular a criatividade e a colaboração fomentando o surgimento } \\
\text { de soluções inovadoras. }\end{array}$ \\
\hline Cardápio de ideias & $\begin{array}{l}\text { Catálogo apresentando a síntese de todas as ideias geradas no } \\
\text { projeto podendo ser incluídas opções para negócios. }\end{array}$ \\
\hline $\begin{array}{l}\text { Matriz de } \\
\text { conhecimento }\end{array}$ & $\begin{array}{l}\text { Ferramenta de análise estratégica de ideias geradas. É utilizada } \\
\text { para validação destas em detrimento de critérios predefinidos bem } \\
\text { como necessidade das personas criadas no projeto. }\end{array}$ \\
\hline Protótipo em papel & $\begin{array}{l}\text { Representações de interface gráficas em diferentes níveis de } \\
\text { fidelidade. }\end{array}$ \\
\hline Storyboard & $\begin{array}{c}\text { Representação visual de uma história por meio de quadros } \\
\text { estáticos. }\end{array}$ \\
\hline Protótipo de serviços & $\begin{array}{l}\text { Refere-se à simulação de artefatos materiais, ambientes ou relações } \\
\text { interpessoais que representem um ou mais aspectos de um serviço } \\
\text { de maneira a envolver o usuário e simular a prestação de serviços. }\end{array}$ \\
\hline
\end{tabular}

Fonte: Adaptado de Vianna (2012)

A escolha da ferramenta a ser utilizada dependerá do tipo de problema a ser resolvido.

\section{MATERIAIS E MÉTODOS}

Este artigo é resultado de uma pesquisa qualitativa, baseada em uma revisão sistemática de literatura - SRL que buscou levantar a bibliografia existente que articula design de serviços e projeto e gestão do ambiente construído. A pesquisa foi organizada em três etapas:

- Etapa 1: Seleção e apresentação das publicações disponíveis sobre design de serviços, ambiente corporativo e qualidade do projeto em português (e em inglês apenas para o termo service design e nas pesquisas da ServDES). As bases pesquisadas foram: Portal de Periódicos da Coordenação de Aperfeiçoamento de Pessoal de Nível Superior (CAPES), Scientific Electronic Library Online - SciELO e Service Design and Innovation Conference - ServDES. As palavras-chave utilizadas foram: Design de serviços, Service design, Ambiente corporativo e Qualidade do 
projeto. As buscas foram realizadas entre 18 de maio de 2019 e 25 de maio de 2019.

- Etapa 2: Síntese dos artigos selecionados a partir das categorias de análise: identificação de números de artigos, período de publicação de 2012 a 2018, títulos, resumo e conclusão.

- Ełapa 3: Discussão sobre as relações entre design de serviço e projeto e qualidade do ambiente construído.

\section{SELEÇÃO E APRESENTAÇÃO DO RESULTADO GERAL DAS BUSCAS}

Foram considerados válidos, para as análises, os trabalhos cujo título, resumo e conclusão eram pertinentes ao estudo do ambiente construído, sendo descartados os que fugiam a este propósito ou estavam repetidos. Abaixo seguem os resultados obtidos.

Quadro 2 - Portal de Periódicos da Coordenação de Aperfeiçoamento de Pessoal de Nível Superior (CAPES)

\begin{tabular}{|c|c|c|c|c|c|}
\hline Palavras-chave & Número Publicações & Títulos & Resumo & Conclusão & Total \\
\hline Design de serviços & 3525 & 43 & 14 & 4 & 4 \\
\hline Service design & 729 & 22 & 8 & 4 & 2 \\
\hline Ambiente corporativo & 1554 & 55 & 17 & 12 & 3 \\
\hline Qualidade do projeto & 347 & 36 & 23 & 4 & 1 \\
\hline Total & & & & & 8 \\
\hline
\end{tabular}

Fonte: a autora

Quadro 3 - Scientific Electronic Library Online - SciELO

\begin{tabular}{|c|c|c|c|c|c|}
\hline Palavras-chave & Número Publicações & Títulos & Resumo & Conclusão & Total \\
\hline Design de serviços & 583 & 34 & 15 & 4 & 2 \\
\hline Service design & 729 & 1215 & 22 & 11 & 2 \\
\hline Ambiente corporativo & 1554 & 18 & 8 & 5 & 2 \\
\hline Qualidade do projeto & 347 & 57 & 9 & 5 & 1 \\
\hline Total & & & & & 7 \\
\hline
\end{tabular}

Fonte: a autora

Quadro 4 - Service Design and Innovation Conference - ServDES

\begin{tabular}{|c|c|c|c|c|c|}
\hline Palavras-chave & Número Publicações & Títulos & Resumo & Conclusão & Total \\
\hline Service design & 232 & 44 & 25 & 13 & 4 \\
\hline Corporate environment & 9 & 9 & 9 & 9 & 6 \\
\hline Qualidade do projeto & 89 & 12 & 12 & 12 & 1 \\
\hline Total & & & & & 11 \\
\hline
\end{tabular}

Fonte: a autora 


\section{SÍNTESE DOS ARTIGOS SELECIONADOS}

Os quadros abaixo sintetizam as informações extraídas dos arquivos selecionados.

Quadro 5 - Portal de Periódicos da Coordenação de Aperfeiçoamento de Pessoal de Nível Superior (CAPES)

\begin{tabular}{|c|c|c|}
\hline Título & Autores & Centralidade \\
\hline $\begin{array}{l}\text { Ambiência: Espaço físico e } \\
\text { comportamento }\end{array}$ & $\begin{array}{l}\text { Maria Luiza T. Bestetti } \\
\text { (2014) }\end{array}$ & $\begin{array}{c}\text { Elementos que compõem o ambiente } \\
\text { construído como condições de } \\
\text { espaço e qualidade. }\end{array}$ \\
\hline $\begin{array}{l}\text { Proposição de um modelo de } \\
\text { referência para o design de } \\
\text { serviços ecoeficientes em sistemas } \\
\text { produto-serviço }\end{array}$ & $\begin{array}{l}\text { Jairo da Costa Junior } \\
\qquad(2012)\end{array}$ & $\begin{array}{c}\text { Desenvolve uma proposição de } \\
\text { Modelo de Referência para o Design } \\
\text { de Serviços. }\end{array}$ \\
\hline "Total Service Design" & $\begin{array}{l}\text { Gillian Hollins e Bill Hollins } \\
\text { (1991) }\end{array}$ & $\begin{array}{c}\text { "Total Design" referindo-se à forma de } \\
\text { gerenciar o processo do design } \\
\text { dentro das organizações de serviços. } \\
\text { Consideram o processo de design } \\
\text { semelhante tanto para produtos } \\
\text { como para serviços. }\end{array}$ \\
\hline $\begin{array}{l}\text { Design de serviços e experiência do } \\
\text { usuário (UX): uma análise do } \\
\text { relacionamento das áreas }\end{array}$ & $\begin{array}{l}\text { Mayara Ramos; Eugenio } \\
\text { Andrés Díaz Merino; } \\
\text { Giselle Schmidt Alves Díaz } \\
\text { Merino; Marcelo (2016) }\end{array}$ & $\begin{array}{c}\text { Analisa ferramentas do design de } \\
\text { serviços aplicadas no processo de } \\
\text { desenvolvimento. }\end{array}$ \\
\hline $\begin{array}{l}\text { Designing Services With Innovative } \\
\text { Methods }\end{array}$ & $\begin{array}{l}\text { Birgit Mager e Michael } \\
\text { Erlhoff }\end{array}$ & $\begin{array}{l}\text { Aplicação dos métodos de projeto } \\
\text { de produto e do design thinking para } \\
\text { o desenvolvimento de serviços. } \\
\text { Design de serviços como agente de } \\
\text { transformação e inovação no } \\
\text { processo de criação de valor. }\end{array}$ \\
\hline $\begin{array}{l}\text { Uma análise bibliográfica e histórica } \\
\text { entre serviços e design de serviços }\end{array}$ & $\begin{array}{l}\text { Danieli Tartas; Eugenio } \\
\text { Andrés Díaz Merino; } \\
\text { Giselle Schmidt Alves Díaz } \\
\text { Merino; Fernando Antonio } \\
\text { Forcellini (2015) }\end{array}$ & $\begin{array}{c}\text { O Design de Serviços como opção } \\
\text { para que as empresas conseguissem } \\
\text { visualizar e melhorar as experiências } \\
\text { dos usuários. }\end{array}$ \\
\hline $\begin{array}{l}\text { Service Design: practical access to } \\
\text { an evolving field. 2005. } 245 \mathrm{f} . \\
\text { Dissertação (Mestrado) - Curso de } \\
\text { European Studies In Design, KISD }\end{array}$ & Moritz, Stefan (2005) & $\begin{array}{l}\text { Design de Serviço conduz e dá } \\
\text { suporte ao serviço de mercado com } \\
\text { novos conceitos. Organizações de } \\
\text { sucesso passaram a ser centradas em } \\
\text { produtos para serviços. }\end{array}$ \\
\hline $\begin{array}{l}\text { Experiência do consumidor no } \\
\text { varejo: Um estudo Bibliométrico }\end{array}$ & $\begin{array}{c}\text { Aline Hopner, Paula } \\
\text { Patrícia Ganzer, Cassiane } \\
\text { Chaves, Pelayo Munhoz } \\
\text { Olea }\end{array}$ & $\begin{array}{c}\text { Experiência do consumidor no } \\
\text { ambiente de loja evidencia as } \\
\text { técnicas capazes de criar } \\
\text { experiências interessantes para os } \\
\text { consumidores. }\end{array}$ \\
\hline
\end{tabular}

Fonte: a autora 
Quadro 6 - Artigos selecionados Scientific Electronic Library Online - SciELO

\begin{tabular}{|c|c|c|}
\hline Título & Autores & Centralidade \\
\hline $\begin{array}{l}\text { A organização do futuro: um novo } \\
\text { modelo para um mundo em } \\
\text { movimento mais rápido }\end{array}$ & Kotter, JP (2014) & $\begin{array}{l}\text { Mudança organizacional, exigência dos } \\
\text { clientes, globalização e competição. }\end{array}$ \\
\hline $\begin{array}{c}\text { Design Para a Inovação Social e } \\
\text { Sustentabilidade }\end{array}$ & Ezio Manzini & $\begin{array}{c}\text { Design de serviços como ferramenta que } \\
\text { pode promover mudanças sustentáveis } \\
\text { (visão sistêmica sobre projeto de serviços, } \\
\text { com abordagem centrada no usuário, } \\
\text { integrando produtos, processos e pontos } \\
\text { de contato). }\end{array}$ \\
\hline $\begin{array}{l}\text { Processes and organizational } \\
\text { innovation for small } \\
\text { businesses. cuad.adm. [online] }\end{array}$ & $\begin{array}{l}\text { Carvalho Proenca, } \\
\text { Joaquin Jose e Jimenez } \\
\text { Saez (2018) }\end{array}$ & $\begin{array}{l}\text { Processos inovadores com colaboração } \\
\text { de usuários. Inovação através da } \\
\text { organizacional e de processos } \\
\text { colaborativos com os usuários. }\end{array}$ \\
\hline Design thinking & Brown, T. (2008) & $\begin{array}{l}\text { Design Thinking (DT), disciplina que usa a } \\
\text { sensibilidade do designer e os métodos de } \\
\text { inovação que concentram o que é } \\
\text { tecnicamente possível e financeiramente } \\
\text { viável do ponto de vista do usuário. }\end{array}$ \\
\hline $\begin{array}{c}\text { Permitindo a inovação de serviços: } \\
\text { uma abordagem de capacidades } \\
\text { dinâmicas }\end{array}$ & $\begin{array}{l}\text { Kindström, D., } \\
\text { Kowalkowski, C. e } \\
\text { Sandberg, E. (2013). }\end{array}$ & $\begin{array}{l}\text { Na inovação como forma de melhorar o } \\
\text { desempenho de empresas de serviços. }\end{array}$ \\
\hline $\begin{array}{l}\text { Service Design: From Insight to } \\
\text { Implementation }\end{array}$ & $\begin{array}{l}\text { Polaine, A.; Løvlie, L.; } \\
\text { Reason, B.( 2013) }\end{array}$ & No objetivo do design de serviços. \\
\hline $\begin{array}{c}\text { Designing Services With Innovative } \\
\text { Methods }\end{array}$ & $\begin{array}{l}\text { Birgit Mager e Michael } \\
\text { Erlhoff }\end{array}$ & $\begin{array}{c}\text { Aplicação dos métodos de projeto de } \\
\text { produto e do design thinking para o } \\
\text { desenvolvimento de serviços. Design de } \\
\text { serviços como agente de transformação } \\
\text { e inovação no processo de criação de } \\
\text { valor. }\end{array}$ \\
\hline "Total Service Design" & $\begin{array}{l}\text { Gillian Hollins e Bill Hollins } \\
\text { (1991) }\end{array}$ & $\begin{array}{l}\text { "Total Design" referindo-se à forma de } \\
\text { gerenciar o processo do design dentro } \\
\text { das organizações de serviços. Consideram } \\
\text { o processo de design semelhante tanto } \\
\text { para produtos como para serviços. }\end{array}$ \\
\hline
\end{tabular}

Fonte: a autora

Quadro 7 - 2012 - Serviços de cocriação

\begin{tabular}{|c|c|c|}
\hline Título & Autores & Centralidade \\
\hline $\begin{array}{c}\text { Incorporando design de serviço: o } \\
\text { longo e o curto }\end{array}$ & Bailey, S., G. & $\begin{array}{c}\text { Design de serviços, inovação, } \\
\text { incorporação, capacidade }\end{array}$ \\
\hline $\begin{array}{c}\text { Passo a passo de serviço para } \\
\text { suporte ao desenvolvimento de } \\
\text { serviços }\end{array}$ & $\begin{array}{c}\text { Blomkvist, J., Åberg, J. \& } \\
\text { Holmlid, S. }\end{array}$ & $\begin{array}{c}\text { Prototipagem de serviços, } \\
\text { desenvolvimento de serviços, serviço } \\
\text { de entrega em domicílio }\end{array}$ \\
\hline $\begin{array}{c}\text { Procurando por Definições para } \\
\text { Design de Serviço - O que }\end{array}$ & Nisula, J. V. & $\begin{array}{c}\text { Codesign, serviços ao consumidor, } \\
\text { ideação on-line, teste de serviço }\end{array}$ \\
\hline
\end{tabular}




\begin{tabular}{|c|c|c|}
\hline $\begin{array}{c}\text { queremos dizer com Serviço? } \\
\text { Desenhar? }\end{array}$ & \\
\hline $\begin{array}{c}\text { Dando Voz ao Design de Serviço na } \\
\text { Sala de Diretoria de } \\
\begin{array}{c}\text { Gerenciamento: Fortalecendo a } \\
\text { Conexão entre Design e } \\
\text { Gerenciamento de Serviço }\end{array}\end{array}$ & Patrício, L. \& Fisk, R. P. & $\begin{array}{c}\text { Design de serviços, design de serviços } \\
\text { interdisciplinares, serviço multinível }\end{array}$ \\
\hline
\end{tabular}

Fonte: a autora

Quadro 8 - 2014 - Futuros serviços

\begin{tabular}{|c|c|c|}
\hline Título & Autores & Centralidade \\
\hline $\begin{array}{c}\text { Design para Inovação de Serviços } \\
\text { Intersetoriais - Quadro Provisório }\end{array}$ & Bettina Minder & $\begin{array}{c}\text { Inovação de serviços, facilitação, } \\
\text { design }\end{array}$ \\
\hline $\begin{array}{c}\text { Informal, Formal, Colaborativo: } \\
\text { identificando novos modelos de } \\
\text { serviços dentro das favelas do Rio } \\
\text { de Janeiro }\end{array}$ & $\begin{array}{c}\text { Maíra Joly, Carla Cipolla, } \\
\text { Ezio Manzini }\end{array}$ & $\begin{array}{c}\text { Design de serviços, inovação social, } \\
\text { comunidades criativas }\end{array}$ \\
\hline $\begin{array}{c}\text { Admirável mundo novo: transições } \\
\text { no design Prática }\end{array}$ & $\begin{array}{c}\text { Joyce Yee, Emma } \\
\text { Jefferies, Lauren Tan }\end{array}$ & $\begin{array}{c}\text { Práticas de mudança, funções de } \\
\text { designers, valor de design, } \\
\text { gerenciamento de design }\end{array}$ \\
\hline $\begin{array}{c}\text { Arquétipos de serviço, uma } \\
\text { consideração metodológica }\end{array}$ & $\begin{array}{c}\text { Stefan Holmlid, Johan } \\
\text { Blomkvist }\end{array}$ & $\begin{array}{c}\text { Ensino, desenho de serviços, estudo de } \\
\text { caso, aprendizagem, aprendizagem } \\
\text { baseada em problemas }\end{array}$ \\
\hline
\end{tabular}

Fonte: a autora

Quadro 9-2016 - Geografias

\begin{tabular}{|c|c|c|}
\hline Título & Autores & Centralidade \\
\hline Formas de Ver o Design de Serviços & $\begin{array}{c}\text { Johan Blomkvist, Simon } \\
\text { Clatworthy e Stefan } \\
\text { Holmlid }\end{array}$ & $\begin{array}{c}\text { Apresenta o material de design e } \\
\text { perspectivas }\end{array}$ \\
\hline $\begin{array}{c}\text { Inovação de Serviços Orientada a } \\
\text { Design - A metodologia para afetar } \\
\text { O significado de um serviço }\end{array}$ & $\begin{array}{c}\text { Masanao Takeyama, } \\
\text { Kahoru Tsukui, Hiroshi } \\
\text { Yamaguchi, Kanako } \\
\text { Matsuo }\end{array}$ & $\begin{array}{c}\text { Inovação orientada para o design, } \\
\text { significado de um serviço, contexto, } \\
\text { inovação de serviços }\end{array}$ \\
\hline $\begin{array}{c}\text { Preparando a organização para } \\
\text { mudança usando conceitos de } \\
\text { serviços }\end{array}$ & $\begin{array}{c}\text { Annita Fjuk, Birgitte Yttri, } \\
\text { Knut Kvale }\end{array}$ & $\begin{array}{c}\text { Conceito de serviço, experiência de } \\
\text { jornada do cliente, negócios } \\
\text { interfuncionais, processos, } \\
\text { pensamentos, design de serviços }\end{array}$ \\
\hline $\begin{array}{c}\text { Serviços para proprietários de } \\
\text { microempresas pobres }\end{array}$ & $\begin{array}{c}\text { Heloisa Candello, Claudio } \\
\text { Pinhanez, David Millen, } \\
\text { Silvia Bianchi }\end{array}$ & $\begin{array}{c}\text { Ferramentas de design de serviços, } \\
\text { processo de design, pesquisa de } \\
\text { campo, colaboração }\end{array}$ \\
\hline $\begin{array}{c}\text { Desafio de Design de Serviço: } \\
\text { Transição do conceito à } \\
\text { implementação }\end{array}$ & Eunji Lee & $\begin{array}{c}\text { Métodos e ferramentas de design de } \\
\text { serviços, processo de desenvolvimento } \\
\text { de serviços, comunicação em design } \\
\text { de serviços }\end{array}$ \\
\hline $\begin{array}{c}\text { Mapeando o que os atores sabem } \\
\text { antegrar recursos }\end{array}$ & $\begin{array}{c}\text { Stefan Holmlid, Petra } \\
\text { Björndal }\end{array}$ & $\begin{array}{c}\text { Lona de informação de serviço, } \\
\text { visualização, diachron, synchron, } \\
\text { conhecimento troca-cocriação. }\end{array}$ \\
\hline
\end{tabular}

Fonte: a autora 
Quadro 10 - 2018 - Prova de Conceito

\begin{tabular}{|c|c|c|}
\hline Título & Autores & Centralidade \\
\hline $\begin{array}{l}\text { Projetando espaços e serviços. } \\
\text { P rojeto experimental para } \\
\text { dormitórios estudantis: do } \\
\text { Politecnico de Milano }\end{array}$ & $\begin{array}{l}\text { Luisa Collina, Peter Di } \\
\text { Sabatino, Laura Galluzzo, } \\
\text { Claudia Mastrantoni }\end{array}$ & $\begin{array}{l}\text { Design de serviços, design do espaço } \\
\text {, codesign, educação de design }\end{array}$ \\
\hline $\begin{array}{c}\text { Métodos e ferramentas de design } \\
\text { de serviços como suporte para a } \\
\text { definição participativa do } \\
\text { metadesign }\end{array}$ & $\begin{array}{l}\text { Davide Fassi, Laura } \\
\text { Galluzzo e Oliver Marlow }\end{array}$ & $\begin{array}{c}\text { Pesquisa em design, projeto do } \\
\text { espaço, , educação em design, } \\
\text { abordagem sistêmica, sistemas de } \\
\text { produtos e serviços }\end{array}$ \\
\hline $\begin{array}{c}\text { Princípios de design para o bem- } \\
\text { estar organizacional: melhorando a } \\
\text { experiência do funcionário através } \\
\text { do design thinking }\end{array}$ & $\begin{array}{l}\text { Barbara Camocini, Luisa } \\
\text { Collina, Laura Daglio, } \\
\text { Martina Mazzarello e } \\
\text { Paola Trapani }\end{array}$ & $\begin{array}{c}\text { Design thinking para o bem-estar da } \\
\text { organização }\end{array}$ \\
\hline $\begin{array}{c}\text { Projetando espaços e serviços. Um } \\
\text { projeto experimental para } \\
\text { dormitórios estudantis: Coletivo } \\
\text { experiências, vidas conectadas e } \\
\text { lugares ligados }\end{array}$ & $\begin{array}{l}\text { Marco Di Norcia, Fabiola } \\
\text { Bertolotti e Matteo Vignoli }\end{array}$ & $\begin{array}{c}\text { Design participativo, envolvimento da } \\
\text { comunidade, codesign, capacidade } \\
\text { e desenvolvimento }\end{array}$ \\
\hline $\begin{array}{l}\text { Os espaços de coworking podem } \\
\text { ser construídos de baixo para cima? }\end{array}$ & $\begin{array}{l}\text { Claudia Mastrantoni, } \\
\text { Luisa Collina, Peter Di } \\
\text { Sabatino e Laura Galluzzo }\end{array}$ & $\begin{array}{l}\text { Design de serviços, design do espaço } \\
\text {, codesign }\end{array}$ \\
\hline $\begin{array}{l}\text { Design thinking para design interior } \\
\text { e espacial: um estudo de caso no } \\
\text { Politecnico di Milano }\end{array}$ & $\begin{array}{l}\text { Vanessa Monna, Giuliano } \\
\text { Simonelli, Francesco } \\
\text { Scullica e Elena Elgani }\end{array}$ & $\begin{array}{l}\text { Design thinking, design de interiores } \\
\text { educação, codesign. }\end{array}$ \\
\hline $\begin{array}{c}\text { Estratégias de engajamento em } \\
\text { ambientes de coprodução, unindo } \\
\text { espaço e organização }\end{array}$ & $\begin{array}{l}\text { Ngoc Pham e Davide } \\
\text { Fassi }\end{array}$ & $\begin{array}{l}\text { Design thinking, design de interiores, } \\
\text { codesign }\end{array}$ \\
\hline $\begin{array}{c}\text { Dança do design: Repensando a } \\
\text { posição, relação e movimento no } \\
\text { design de serviços }\end{array}$ & Ricardo Saint-Clair & $\begin{array}{l}\text { Ambientes de cocriação, desenho do } \\
\text { espaço, desenho organizacional }\end{array}$ \\
\hline Rastreios como prova de serviço & $\begin{array}{l}\text { Johan Blomkvist e Fredrik } \\
\text { Wahlman }\end{array}$ & $\begin{array}{l}\text { Passo a passo, facilitação, } \\
\text { ferramentas, codesign }\end{array}$ \\
\hline $\begin{array}{l}\text { Service + Spatial design: } \\
\text { Introduzindo os fundamentos de } \\
\text { uma abordagem transdisciplinar }\end{array}$ & Costas Boletsis & $\begin{array}{l}\text { Experiência em prototipagem, design } \\
\text { de serviços, prototipagem de serviços }\end{array}$ \\
\hline $\begin{array}{c}\text { Design de espaço e serviço na } \\
\text { prática educativa }\end{array}$ & $\begin{array}{c}\text { Davide Fassi, Laura } \\
\text { Galluzzo e Annalinda De } \\
\text { Ros }\end{array}$ & $\begin{array}{c}\text { Design de serviços, Educação, } \\
\text { Espaço }\end{array}$ \\
\hline $\begin{array}{c}\text { Design de espaço e serviços na } \\
\text { educação prática }\end{array}$ & Nansi van Geetsom & $\begin{array}{l}\text { Design de serviços, design de } \\
\text { interiores, abordagens educacionais, } \\
\text { design de espaços e serviços, } \\
\text { desafios do design }\end{array}$ \\
\hline $\begin{array}{l}\text { Iniciando comunidades em } \\
\text { espaços habitacionais }\end{array}$ & Giordana Ferri & $\begin{array}{c}\text { Moradia, comunidade, espaços } \\
\text { compartilhados }\end{array}$ \\
\hline
\end{tabular}

Fonte: a autora

\section{DISCUSSÃO E CONSIDERAÇÕES FINAIS}

A partir dos dados coletados na RSL, pode-se compreender que um dos maiores desafios no âmbito do planejamento e arquitetura é o "déficit de comunicação entre a equipe de design, e os diferentes níveis de grupos de usuários" (COLLINA et al., 2018, p. 9). Para resolver este problema na economia 
de serviços, uma alternativa eficaz que combina o design de aspectos tangíveis e intangíveis é o design de serviços. Como uma ferramenta de inovação predominantemente de gestão, ele capacita os designers para gerar soluções inovadoras frente a problemas antigos (MERONI; SANGIORGI, 2011 ), (BROWN, 2008).

A RSL demonstrou ainda que as principais referências para o estudo de design de serviços continuam sendo Gillian Hollins e Bill Hollins da Escola de Negócios Westminter, Reino Unido; Michael Erlhoff e Birgit Mager, da University of Applied Sciences Cologne, na Alemanha; e E zio Manzini no Politécnico de Milão, da Itália. Em comum entre eles está o fato de serem precursores do design de serviços e de reunirem a preocupação com as competências projetuais como Manzini e Mager Erlhoff e a gestão como Hollins e Hollins.

Contudo, a base de pesquisa na qual concentra-se a maior parte de publicações destinadas a compreender sua relação com o espaço do ambiente corporativo é ServDES, sobretudo a partir da edição de 2018. Diante disso, concluiu-se que para fazer do projeto e qualidade do ambiente corporativo condizentes com as necessidades dos usuários, ele precisa ser compreendido do ponto de vista da competência projetual e de gestão, a fim de se tornar um espaço criativo, multidisciplinar e integrado.

\section{REFERÊNCIAS}

BROWN, T. Design thinking. Harvard Business Review, [s. I.], v. 86, n. 6, p. 85-92, jun. 2008.

COLLINA, L. et al. Designing spaces and services. An experimental project for student dormitories: Collective experiences, connected lives and linked places. In: ServDes2018, 6., 2018, Milão. Conference Archive [...]. Milão: Politecnico di Milano, 2018. Tema: Proof of Concept, p. 751-760. Disponível em: <http://www.servdes.org/wp/wp-content/uploads/2018/07/63.pdf>. Acesso em: 13 dez. 2018.

FASSI, D.; GALLUZZO, I.; MARLOW, O. Experiencing and shaping: the relations between spatial and service design. In: ServDes2018, 6., 2018, Milão.

Conference Archive [...]. Milão: Politecnico di Milano, 2018. Tema: Proof of Concept, p. 717-725. Disponível em: <http://www.servdes.org/wp/wpcontent/uploads/2018/07/60.pdf>. Acesso em: 13 dez. 2018.

HINNIG R.; FIALHO, F. A. P. Design de serviços no setor público: um estudo de caso do projeto Make It Work na cidade de Sunderland (Inglaterra). Estudos em Design Revista (online), Rio de Janeiro, v. 21 Disponível em: <https://www.maxwell.vrac.pucrio.br/22412/22412.PDFXXvmi=p7bBN5Z7L2VUm 6ZVodvBgcgfvoMEWeAWmMxaSxiEAfzWmzTLNqm4DDka37PAmpxJd6U6EdKfskd PT7CHzZMdD7n>. Acesso em: 12 set. 2018.

IDSA - Industrial Designers Society for América. 2012. Disponível em: <https://www.idsa.org/>. Acesso em: 10 jun. 2019.

MERONI, A.; SANGIORGI, D. Design for services: design for social responsibility series. Series Editor: Rachel Cooper Gower, 2013.

MORITZ, S. Service design: practical access to an evolving field. Germany: Köln International School of Design, 2005. 
MOZOTA, B. B. Gestão Do Design: Usando o design para construir valor de marca e inovação corporativa. Porto Alegre: Bookman, 2010.

PINE, B. J. Il; GILMORE, J. H. Welcome to the Experience Economy. Harvard Business Review, 1998.

PINHEIRO, T. D. The service startup: inovação e empreendedorismo através do design thinking. Rio de Janeiro: Alta Books, 2015.

STICKDORN, M.; SCHNEIDER, J. Isto é design thinking de serviços: fundamentos, ferramentas, casos. Porto Alegre: Bookman, 2014.

UNANUE, M. A memória e as referências projetuais na construção de conhecimento em arquitetura. 2013. Disponível em:

<http://projedata.grupoprojetar.ufrn.br/dspace/handle/123456789/1869>. Acesso em: 15 jan. 2019.

TELLINI, I. et al. Design thinking em serviço: uma revisão sistemática da literatura. In: SEMEAD - Seminários em Administração, 19., 2016. Anais [...]. Disponível em: <http://login.semead.com.br/19semead/anais/arquivos/643.pdf>. Acesso em: 12 abr. 2019.

VIANNA, M. Design thinking: inovação em negócios. Rio de Janeiro: MJV Press, 2012. Disponível em: <http://centrodeinovacaodemaringa.org.br/wpcontent/uploads/2017/08/Livro_Design_Thinking_-_Inovao_Negcios.pdf>. Acesso em: 3 abr. 2019. 